\title{
Heat Disposal through Horizontal Submerged Jets
}

\author{
Mohammed A. Azim \\ Department of Mechanical Engineering, Bangladesh University of Engineering and Technology, Dhaka, Bangladesh
}

\begin{abstract}
The governing equations for submerged buoyant jet are solved numerically using the standard $k-\varepsilon$ model for turbulence closure. Comparison shows that results from simulation of this jet in quiescent ambient are in good agreement with the existing data. Simulation is also performed for this submerged jet in moving ambient for the seasonal conditions of a typical steam power plant situated nearby a river. Study of trajectories and excess temperatures of the jets in moving ambient show small vertical rises for the regulated excess temperatures over the year.
\end{abstract}

Keywords: Heat Disposal, Submerged Jet, Turbulent, Seasonal Condition

\section{Introduction}

The waste heat from thermal and nuclear power plants are disposed by means of submerged outfalls in the nearby coast or river. These submerged outfalls are the turbulent buoyant jets which have been investigated extensively by many researchers e.g. Albertson et al. [1], Fan [2], Anwar [3], Fischer et al. [4], Rodi [5], Wood et al. [6], Guo et al. [7], and Michas and Papanicolaou [8]. Horizontal buoyant jets as in Fig.1 are commonly used because for a specific discharge depth, a longer jet trajectory appears and subsequently greater amount of ambient fluid entrains and mixes with the jet fluid compared to outfalls with vertical risers. Moreover, horizontal buoyant jets are free from re-entrainment problem which occurs in vertical risers.

In waste heat disposal, any temperature rise of the receiving water beyond specified values may cause harm to aquatic life with the change in dissolved oxygen concentration. Such heat removal from power plant is done simply by running a large amount of coastal water through the condensers in a single pass and discharging it back into the coastal water. The discharge is made through horizontal jet that requires minimum area in the receiving water for its rapid dilution to a legal value. This type of cooling can save the cost of power generation. Many power plants, thermal and nuclear, have higher net output in winter than summer due to differences in cooling water temperature. However, in discharging back the cooling water at constant rate, the proportion between the velocity and flow area is crucial. This is because high velocity of a buoyant jet incurs an irrecoverable loss of power as the entire kinetic energy of the jet dissipates into the ambient fluid by interaction with the boundary [1].

Present simulation is performed on round turbulent buoyant jets that discharge horizontally into a quiescent or initially coflowing body of water. The governing equations are solved for the conditions taken from a typical steam power plant project in Bangladesh situated near by a river whose water speed and temperature vary as $1-3 \mathrm{~m} / \mathrm{s}$ and $21.5-27.5^{\circ} \mathrm{C}$ from dry to wet season. Considering ecosystem, the local seasonal temperature of the coastal water usually must not exceed $2-4^{\circ} \mathrm{C}[8]$.

The paper is organized as follows: description of the governing equations and computational techniques, reporting of a typical power plant ecosystem related to waste heat disposal, comparison of the results extracted from present simulations with those of existing literature and summarization of the work in the conclusion.

\section{Governing Equations}

The geometrical axis of a submerged hot water jet is deflected by the buoyancy force in transverse direction that renders streamwise curvature to the jet. This deflected geometrical axis coincides with $s$-coordinate of the streamline co-ordinates $(s, y)$ as in Fig. 1. Thus the equations governing the round turbulent buoyant jet flow $(\overline{u, v})$ for constant property fluid under thin shear layer approximation are

$$
\begin{aligned}
& \frac{\partial}{\partial s}\left(\begin{array}{c}
- \\
y u
\end{array}\right)+\frac{\partial}{\partial y}\left(\begin{array}{c}
- \\
y v
\end{array}\right)=0 \\
& -\frac{\partial \phi}{\partial s}+\frac{-\partial \phi}{\partial y}=\frac{1}{y} \frac{\partial}{\partial y}\left(v y N_{\phi} \frac{\partial \phi}{\partial y}\right)+S_{\phi}
\end{aligned}
$$

Fax: 880-2-9665636; E-mail: azim@me.buet.ac.bd

(C) 2015 International Association for Sharing Knowledge and Sustainability

DOI: $10.5383 /$ ijtee. 10.02 .010 


$$
{ }^{=} 2 \frac{d \theta}{d s}=\left(\frac{\rho_{a}-\rho}{\rho_{o}}\right) g \operatorname{Cos} \theta
$$

where $\phi$ is the general flow variable that represents the mean velocity $\bar{u}$, mean temperature $\bar{t}$, turbulence kinetic energy $k$ and viscous dissipation rate $\varepsilon$. Here $u$ and $\rho$ are the space average quantities over the jet cross-section, $v$ is the fluid viscosity, $g$ is the gravitational acceleration, and $\theta$ is the angle of trajectory deflection. The transport coefficient $N_{\phi}$ and the source term $S_{\phi}$ are described in Table 1. There $\rho_{o}$ and $\rho_{a}$ are the densities of jet and ambient fluids, $A_{s}=\beta \alpha_{t} g \operatorname{Cos} \theta$ $. \bar{t} / \partial y$ and $\beta$ is the coefficient of volume expansion.

Table 1. Expressions of $N_{\phi}$ and $S_{\phi}$

\begin{tabular}{ccc}
\hline$\phi$ & $N_{\phi}$ & $S_{\phi}$ \\
\hline$u$ & $\left(v+v_{t}\right) / v$ & $\left(\rho_{a}-\rho\right) \rho_{o}^{-1} g \operatorname{Sin} \theta$ \\
$t$ & $\left(\alpha+\alpha_{t}\right) / v$ & 0 \\
$\rho$ & $\left(\gamma+\gamma_{t} / \sigma_{\gamma}\right) / v$ & 0 \\
$k$ & $\left(v+v_{t} / \sigma_{k}\right) / v$ & $v_{t}(\partial u / \partial y)^{2}-A_{s}-\varepsilon$ \\
$\varepsilon$ & $\left(v+v_{t} / \sigma_{\varepsilon}\right) / v$ & $C_{1}(\varepsilon / k)\left[v_{t}(\partial \bar{u} / \partial y)^{2}-\right.$ \\
& & $\left.C_{3} A_{s}\right] / k-C_{2} \varepsilon^{2} / k$ \\
\hline
\end{tabular}

Although temperature variation gives rise to variation in the properties of fluid, these variations are ignored completely following Boussinesq approximation. Variation of density of the fluid is considered only when this causes a body force. Equation (3) is derived from the momentum balance normal to the streamline co-ordinate along with order of magnitude arguments. This equation may be interpreted as a force balance on a stream tube being deflected by the buoyancy force in the transverse direction. In buoyant jet, fluctuating turbulent quantities are negligible compared to the mean centerline quantities [9-10]. The static pressure is assumed to be $\bar{p}=\rho_{a} g\left(h_{j}-y \operatorname{Cos} \theta\right)$ as the pressure in the free jet is close to the hydrostatic pressure that prevails outside the jet proper where $h_{j}$ is the depth of jet exit from the water surface.

\subsection{Turbulence Closure}

The standard $k-\varepsilon$ model [11] is used here for achieving turbulence closure. In this model, eddy viscosity is expressed by the Kolmogorov-Prandtl relation as

$$
v_{t}=C_{\mu} k^{2} / \varepsilon
$$

and the closure coefficients appearing in Eq. (2) are $C_{\mu}=0.09$, $\sigma_{k}=1.0, \sigma_{\varepsilon}=1.3, C_{I}=1.44$ and $C_{2}=1.92$. The coefficient $C_{3}$ cannot be used as a constant but calculated after Henkes et al. [12] as $C_{3}=\tanh |\bar{u} / \bar{v}|$. Further, molecular and turbulent diffusivities for heat and momentum are assumed to be related by $\alpha=v / P_{r}$ and $\alpha_{t}=v_{t} / P_{r t}$. For water $v=0.7 \times 10^{-6} \mathrm{~m}^{2} / \mathrm{s}$, $\beta=3.62 \times 10^{-4} \mathrm{~K}^{-1}$, molecular Prandtl number $P_{r}=4.62$ and turbulent Prandtl number $P_{r t}=0.6$.

\subsection{Initial and Boundary Conditions}

The initial conditions are $\bar{u}\left(0, y \leq r_{o}\right)=u_{o}, \bar{t}\left(0, y \leq r_{o}\right)=t_{o}$, $\bar{t}\left(0, y>r_{o}\right)=t_{a}$ and $\overline{u^{\prime} v^{\prime}}(0, y)=k(0, y)=\varepsilon(0, y)=0$. The boundary conditions are $\bar{u}(s, y \geq b)=u_{a} \operatorname{Cos} \theta$ and at the outflow $\partial \phi / \partial s=0$. Here $r_{o}$ is the jet exit radius, $b$ is the distance of outer jet boundary from $s$-axis, $u_{o}$ and $t_{o}$ are the jet exit velocity and temperature, $u_{a}$ and $t_{a}$ are the ambient fluid velocity and temperature.

\section{Numerical Procedure}

The governing equations (1)-(4) are solved using Fully Implicit Numerical Scheme [13] and Tridiagonal Matrix Algorithm [14] with second-order upwind interpolation for the convective terms in Eq. (2). This numerical scheme is second order accurate and provides converged solution in 19 iterations which is up to six decimal places for the mean velocity $\bar{u} / u_{o}$. The computational domain of the present work can be visualized in Fig. 1. Grid spacing is variable both in $s$ and $y$ directions such that $\Delta s_{i+l}=K \Delta s_{i}, \Delta y_{j+l}=K \Delta y_{j}, \Delta s_{l}=2 \Delta y_{l}$ and

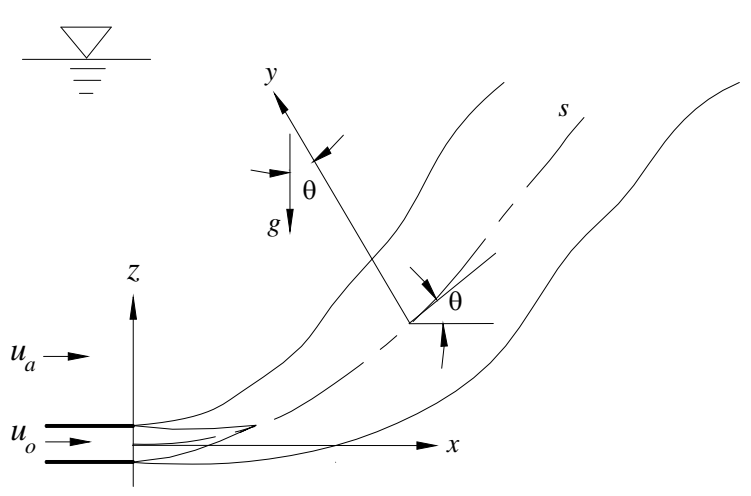

Fig. 1. Schematic of a submerged buoyant jet and streamline coordinate system.

$$
\Delta y_{1}=r_{o}(K-1) /\left(K^{n j-1}-1\right)
$$

where $K=1.04$ and $n j$ is the number of grid points over $r_{o}$. The under-relaxation factors used for $\bar{u}, \bar{v}, N_{u}, \bar{t}$ and $\bar{\rho}$ are individually 0.6 while for $k$ and $\varepsilon$ are 0.8 . 


\subsection{Grid Convergence Test}

Grid convergence test is carried out with the three grid sizes termed as coarse, medium and fine for $n j$ equal to 41,51 and 61 , respectively. Figure 2 shows the turbulence kinetic energy (TKE) profiles of the buoyant jet in quiescent ambient at the location of $s / d=1$ for the three different grid resolutions where $d$ is jet diameter at exit. Results due to three grid sizes are very close to each other except a little difference near the jet axis. However, the results presented in this paper are obtained by using the fine grid.

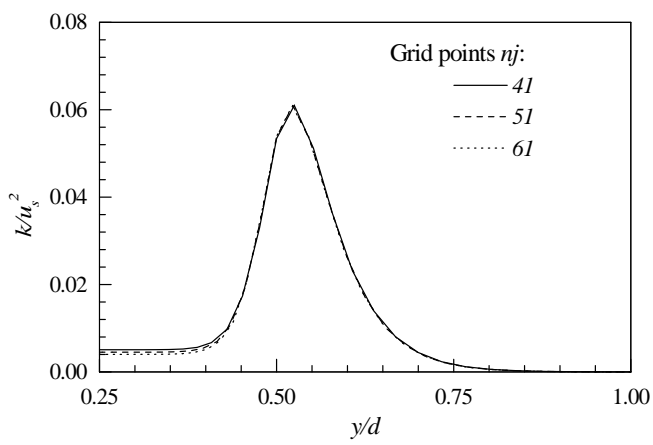

Figure 2. TKE profiles of buoyant free jet at $s / d=1$.

\section{Results and Discussion}

Submerged horizontal buoyant jet has been studied in quiescent ambient with $u_{o}=6 \mathrm{~m} / \mathrm{s}, t_{o}=37.5^{\circ} \mathrm{C}$ and $t_{a}=27.5^{\circ} \mathrm{C}$. Development of the jet $\left(R_{e}=8.5 \times 10^{5}\right.$ and $\left.F_{o}=114\right)$ in terms of jet width, centerline velocity, mean axial velocity and normalized dilution are presented in this section, and compared with the existing data $[1,6,8,15]$. Here $R_{e}=u_{s} d / v$ is the Reynolds number and $F_{o}=(4 / \pi)^{0.25} u_{s} / \sqrt{\left(1-\rho_{o} / \rho_{a}\right) g d}$ is the initial Froude number. This submerged jet has been investigated further in moving ambient for the conditions taken from a typical steam power plant project as stated in Sect. 1. The project estimates to discharge the cooling water at a temperature of $37.5^{\circ} \mathrm{C}$ in the nearby river water whose speed and temperature range $1-3 \mathrm{~m} / \mathrm{s}$ and $21.5-27.5^{\circ} \mathrm{C}$ from dry to wet season. While considering the ecosystem, Department of Environment (DOE) in Bangladesh specified the costal water temperature to be $20-30^{\circ} \mathrm{C}$. The governing equations are solved for jets at constant and variable discharge velocities in moving ambient as shown in Table 2. The characteristics of submerged buoyant jet in moving ambient are also presented in this section in terms of jet trajectory and centerline excess temperature over the ambient in horizontal and vertical directions.

Table 2. Seasonal plant conditions

\begin{tabular}{cccc}
\hline$u_{o}(\mathrm{~m} / \mathrm{s})$ & $u_{a} / u_{o}$ & $t_{a}\left({ }^{\circ} \mathrm{C}\right)$ & $F_{o}$ \\
\hline \multirow{2}{*}{6} & 0.167 & 21.5 & 78 \\
& 0.333 & 24.5 & 69 \\
& 0.5 & 27.5 & 58 \\
\hline 2 & & 21.5 & 16 \\
4 & 0.5 & 24.5 & 34 \\
6 & & 27.5 & 58 \\
\hline
\end{tabular}

\subsection{Buoyant Jet in Quiescent Ambient}

Growth of jet width $b_{e}$ is plotted in Fig. 3 against axial distance $s / d$. The width $b_{e}$ is the transverse distance from the jet axis at which mean velocity reduces to $1 / e$ of the centerline velocity where the number $e=2.718$. Present simulation shows linear growth of the jet width at $s / d>6$ with a slope of 0.082 which is somewhat less than the existing values $[1,6]$. Such less value is likely due to a coflow of $7 \%$ of the initial jet velocity [15]. Although the jet is assumed in quiescent ambient, a little coflow is required in the computation to maintain momentum flux constancy over the large axial distance.

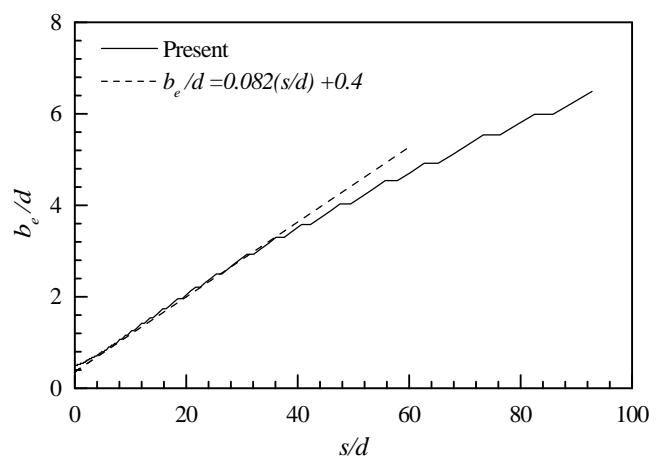

Figure 3. Growth of jet width.

Axial decay of centerline mean velocity $u_{c}$ is shown in Fig. 4 that follows the inverse relation with downstream distance given by $\left(u_{c}-u_{a}\right) / u_{s}=K_{u}(s / d)^{-1}$ where $K_{u}=6.2$ in [1] and $K_{u}=6.7$ in [6]. Present simulation shows $K_{u}=5.2$ that is lower than those values. This is because of the coflow as already mentioned [15].

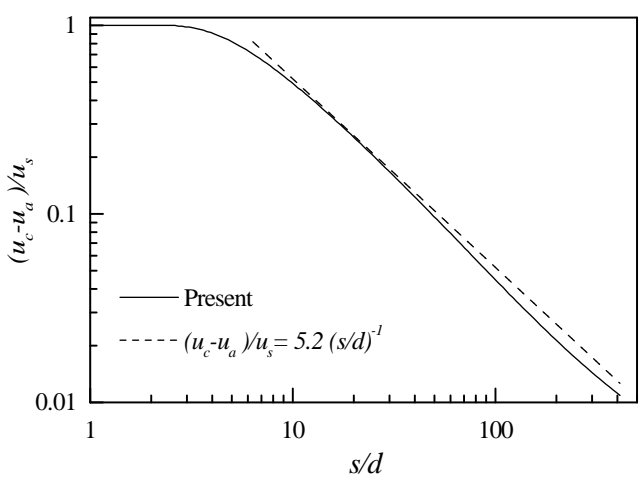

Figure 4. Decay of mean centerline velocity.

Mean axial velocity profiles are displayed in Fig. 5 in similarity co-ordinates $\left(u-u_{a}\right) /\left(u_{c}-u_{a}\right)$ and $y / b_{e}$ at $s / d=30$ and 60 , and found in good collapse from the jet axis outward. The figure also shows that simulated mean velocity profiles are very nearly Gaussian as $\left(u-u_{a}\right) /\left(u_{c}-u_{a}\right)=\exp \left(-y^{2} / b_{e}^{2}\right)$. 


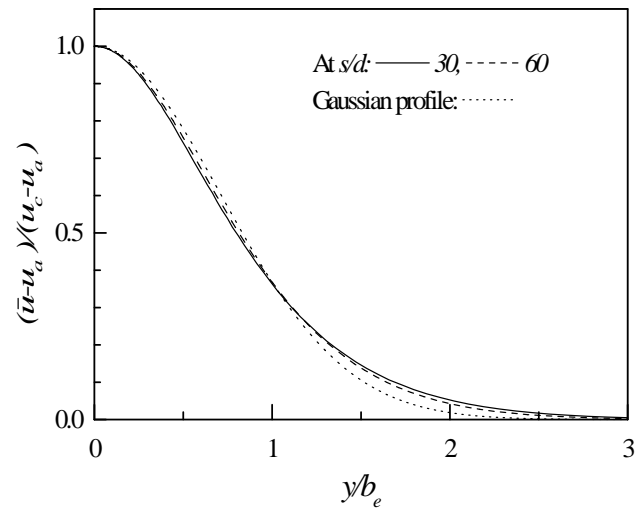

Figure 5. Mean axial velocity profiles at different $s / d$.

Normalized centerline temperature dilution $S / F_{o}$ is presented as a function of normalized elevation $z / l_{M}$ in Fig. 6. Here $S=\left(t_{o}-t_{a}\right) /\left(t_{c}-t_{a}\right)$ is the centerline dilution and $l_{M}=(4 / \pi)^{0.25} u_{s} / \sqrt{\left(1-\rho_{o} / \rho_{a}\right) g d^{-1}}$ is the length scale. Michas and Papanicolaou [8] data added for comparison show a little disagreement with those of present simulation which may be due to the small coflow.

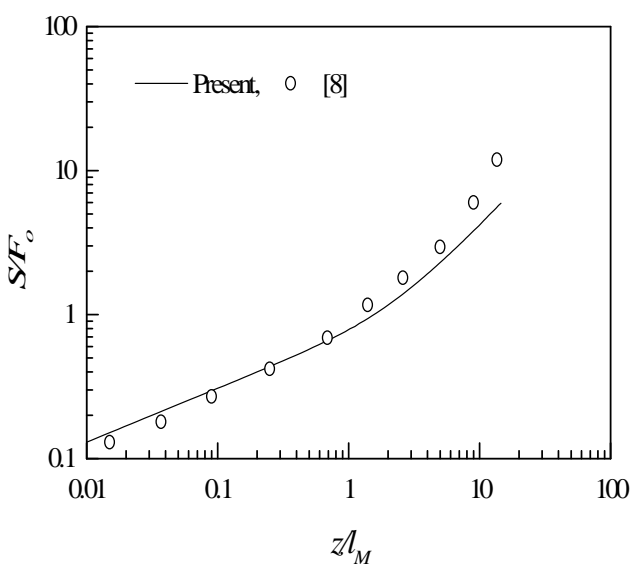

Figure 6. Normalized centerline dilution against vertical rise.

\subsection{Buoyant Jet in Moving Ambient}

Trajectories (centerlines) of buoyant jets are shown in Figs. 7-8 for the horizontal jets in moving ambient with constant and variable discharge velocities. The figures illustrate that the trajectories for constant discharge velocity are not significantly affected by the changes in $u_{a}$ and $t_{a}$ while for variable discharge velocity are significantly affected. This is due to less variation in $F_{o}$ at constant jet velocity compared to that at variable jet velocity shown in Table 2 . Figure 7 exhibits that the trajectories with increasing $F_{o}$ travel a little horizontal distances before they bend over to approach vertical movement while Fig. 8 exhibits traveling of long horizontal distances This is because for identical variation in initial buoyancy flux, the former jets experience less variation in initial momentum flux compared to the latter ones.

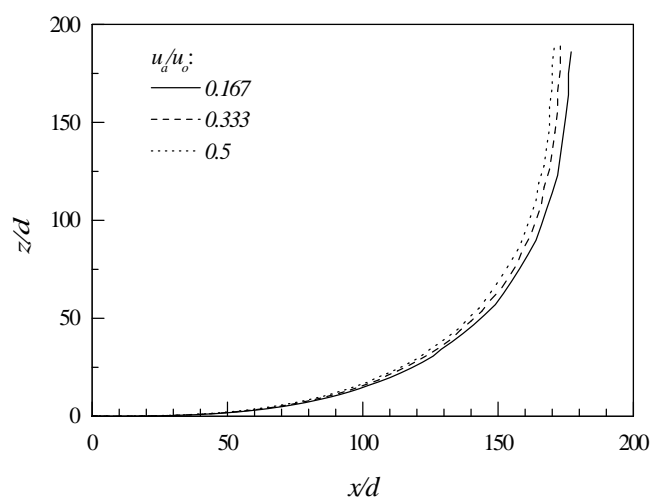

Figure 7. Trajectories of buoyant jet for $u_{o}=6 \mathrm{~m} / \mathrm{s}$.

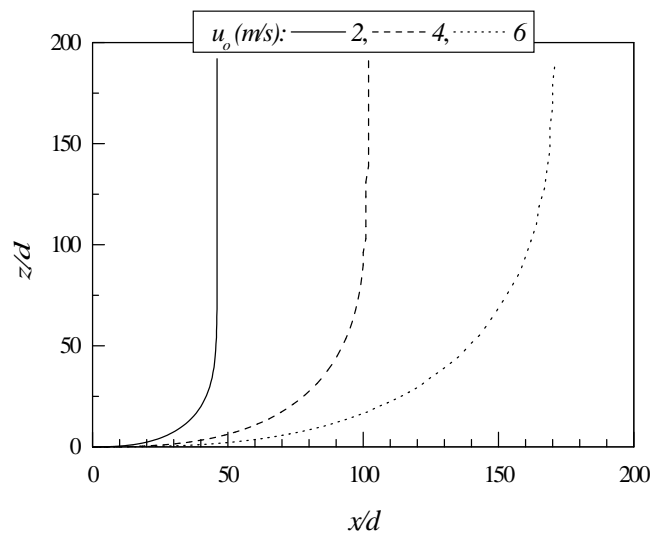

Figure 8. Trajectories of buoyant jet for $u_{a} / u_{0}=0.5$.

Centerline excess temperature $\Delta t_{c}$ is the centerline temperature above the ambient one as plotted in Figs. 9-12 against horizontal distance $x / d$ and vertical distance $z / d$. As the coastal water usually must not exceed $2-4^{\circ} \mathrm{C}$ above the seasonal temperature [8] and should comply with DOE specified temperature, presentation of excess temperature against $x / d$ and $z / d$ seems important to make the real situation discernible. The excess temperature lines at constant discharge velocity merge into a single line at $x / d>30$ and $\Delta t_{c} \leq 2^{\circ} \mathrm{C}$ in Fig. 9 and at $z / d>0.026$ and $\Delta t_{c} \leq 6^{\circ} \mathrm{C}$ in Fig. 10. While those lines at variable discharge velocity in Figs. 11-12 merge at large distances not before $\Delta t_{c}$ is nearly zero. On the one hand, at constant discharge velocity for $\Delta t_{c}=4^{\circ} \mathrm{C}$ in dry season the jet travels horizontally to $x / d=14.7$ and vertically to $z / d=0.05$, and for $\Delta t_{c}=2^{\circ} \mathrm{C}$ in wet season the jet travels to $x / d=27.3$ and $z / d=0.35$. On the other hand, at variable discharge velocity for $\Delta t_{c}=4^{\circ} \mathrm{C}$ in dry season the jet travels to $x / d=20.6$ and $z / d=2.7$, and for $\Delta t_{c}=2^{\circ} \mathrm{C}$ in wet season travels to $x / d=12.4$ and $z / d=0.72$. 


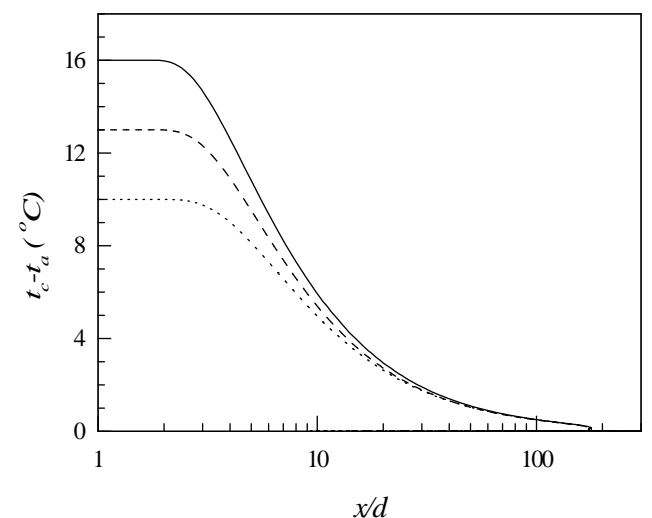

Figure 9. Excess temperature over ambient for $u_{o}=6 \mathrm{~m} / \mathrm{s}$. Lines as in Fig. 7

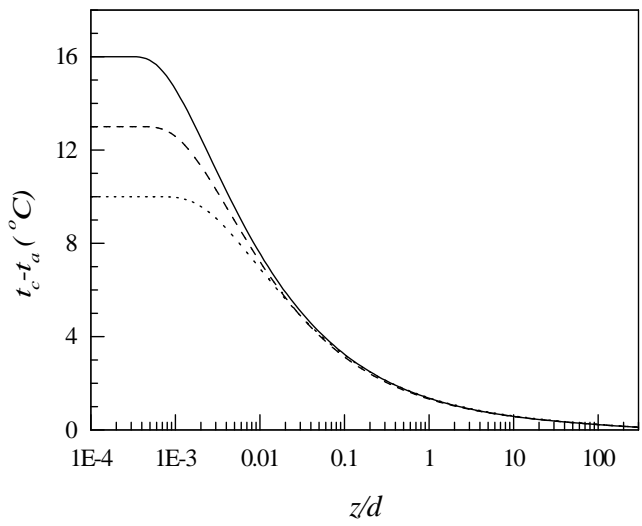

Figure 10. Excess temperature over ambient for $u_{o}=6 \mathrm{~m} / \mathrm{s}$. Lines as in Fig. 7

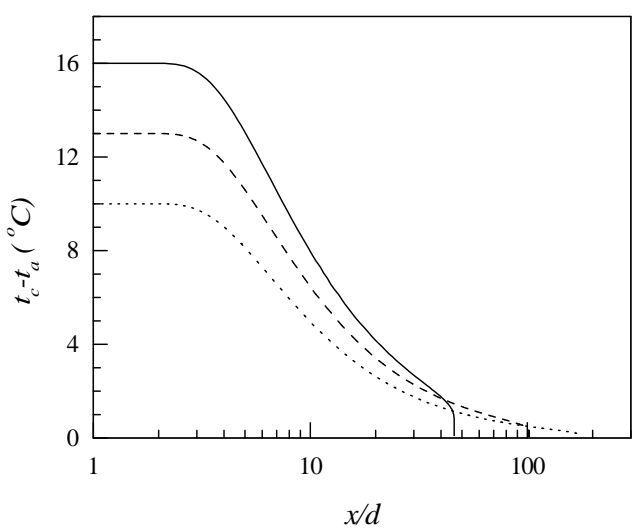

Figure 11. Excess temperature over ambient for $u_{a} / u_{o}=0.5$. Lines as in Fig. 8

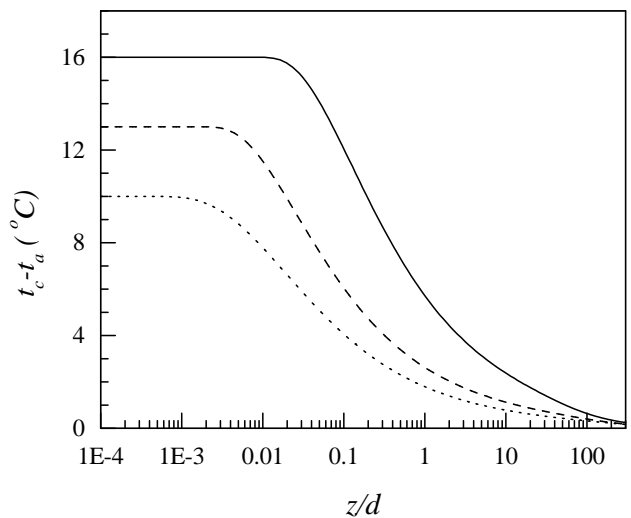

Figure 12. Excess temperature over ambient for $u_{a} / u_{o}=0.5$. Lines as in Fig. 8

\section{Conclusion}

Submerged turbulent buoyant jets that discharge horizontally into a quiescent or initially coflowing body of water are investigated numerically. Obtained results for jet width, centerline velocity decay, transverse profile of axial velocity and centerline temperature dilution of the jet in quiescent ambient are compared with the existing data and found in good agreement. Simulation of jets in initially coflowing ambient for the seasonal conditions of the steam power plant led to the conclusion that the trajectories of the horizontal jets with constant discharge velocity bend nearly at the same horizontal distances throughout the year while jets with higher exit momentum in case of variable discharge velocity bend at longer horizontal distances. Furthermore, the submerged jets require short vertical distances for the centerline excess temperature of $2-4^{\circ} \mathrm{C}$ around the year, except for $4^{\circ} \mathrm{C}$ in dry season with a discharge velocity of $2 \mathrm{~m} / \mathrm{s}$, indicating that the recipient of disposed heat may be a shallow water body.

\section{Nomenclature}

$b_{e} \quad$ value of $y$ at $\bar{u}=0.37 u_{c}$

$F_{o} \quad$ initial Froude number

$k \quad$ turbulence kinetic energy

$l_{M} \quad$ characteristic length scale

$N_{\phi} \quad$ transport coefficient

$n j \quad$ number of grid points over $r_{o}$

$\bar{p} \quad$ pressure inside the jet

$P_{r} \quad$ molecular Prandtl number

$R_{e} \quad$ Reynolds number

$r_{o} \quad$ jet radius at exit

$S \quad$ temperature dilution

$S_{\phi} \quad$ source term

$s, y \quad$ streamline co-ordinates in Fig. 1 


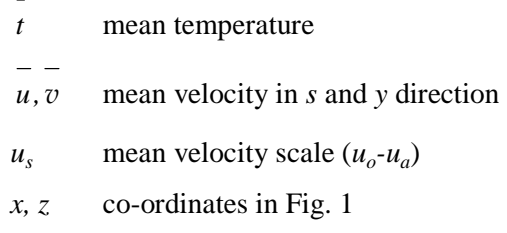

\section{Subscripts}

$\begin{array}{ll}a & \text { ambient fluid } \\ c & \text { jet centerline } \\ o & \text { at jet exit } \\ t & \text { turbulent }\end{array}$

\section{References}

[1] Albertson, M.L., Dai, Y.B., Jensen, R.A., and Rouse, H., 1950, "Diffusion of Submerged Jets," ASCE Trans. 115, pp. 639-697.

[2] Fan, L.N., 1967, "Turbulent Buoyant Jets into Stratified or Flowing Ambient Fluids," Rep. No. KH-R-15, Calif. Inst. Technol., USA.

[3] Anwar, H.O., 1969, "Behavior of a Buoyant Jet in a Calm Fluid," Proc. ASCE, J. Hyd. Div. 95(4), pp. 12891303.
[4] Fischer, H.B., List, E.J., Koh, R.C.Y., Imberger, J., and Brooks, N.H., 1979, "Mixing in Inland and Coastal Waters," Academic Press, London.

[5] Rodi, W., 1982, Turbulent Buoyant Jets and Plumes, Pergamon Press, Oxford.

[6] Wood, I.R., Bell, R.G., and Wilkinson, D.L., 1993, Ocean Disposal of Wastewater, Advanced Series on Ocean Eng. 8, World Scientific, Singapore.

[7] Guo, Y., Malcangio, D., Davies, P.A., and Fernando, H.J.S., 2005, "A Laboratory Investigation into the Influence of a Localized Region of Turbulence on the Evolution of a Round Turbulent Jet," Fluid Dyn. Res. 36, pp. 75-89.

[8] Michas, S.N., and Papanicolaou, P.N., 2009, "Horizontal Round Heated Jets into Calm Uniform Ambient," Desalination 248(1), pp. 803-815.

[9] Abramovich, G.N., 1963, The Theory of Turbulent Jets, MIT Press, Cambridge, Massachusetts.

[10] Schlichting, H., 1968, Boundary Layer Theory, McGraw Hill, New York.

[11] Launder, B.E., and Spalding, D.B., 1974, "The Numerical Computation of Turbulent Flows," Comput. Methods in Appl. Mech. Eng. 3, pp. 269-289.

[12] Henkes, R.A.W.M., van der Flugt, F.F., and Hoogendoorn, C.J., 1991, "Natural Convection Flow in a Square Cavity Calculated with Low Reynolds Number Turbulence Models," Int. J. Heat Mass Transfer 34, pp. 1543-1557.

[13] Anderson, D.A., Tannehill, J.C., and Pletcher, R.H., 1984, Computational Fluid Mechanics and Heat Transfer, McGraw-Hill, NewYork.

[14] Thomas, L.H., 1949, "Elliptic Problems in Linear Difference Equations Over a Network," Watson Sci Comput Lab Report, Columbia University, New York.

[15] Rajaratnam, N., 1976, Turbulent Jets, Developments in Water Science 5, Elsevier, Armsterdam, Netherlands. 